\title{
Produtividade de alface orgânica em diferentes densidades de plantas
}

\author{
Yield of organic lettuce in different plants density
}

'Programa de Pós-graduação em Agronomia Produção Vegetal, Universidade Federal do Acre (UFAC) BR 364, Km 04, Distrito Industrial, CEP 69920-900, Rio Branco, AC, Brasil

${ }^{2}$ Departamento de Agronomia, Universidade Federal do Acre (UFAC), Rio Branco, AC, Brasil

${ }^{3}$ Bolsista de produtividade em pesquisa do CNPq, nível PQ - 1D ${ }^{4}$ Secretaria Municipal de Agricultura Rio Branco, AC, Brasil

${ }^{5}$ Departamento de Agronomia,

Universidade Federal do Acre, Rio

Branco, AC, Brasil

*autor correspondente

$\Delta$ reginalff@yahoo.com.br

\section{Introdução}

A alface (Lactuca sativa L.) tem ampla adaptação a diversos ambientes, baixo custo de produção, baixa suscetibilidade a pragas e doenças, fácil manejo, ciclo curto, alta produtividade e rentabilidade econômica, que fazem desta hortaliça uma das mais cultivadas em todas as regiões brasileiras (MEDEIROS et al., 2007; SOUZA et al., 2007; ZÁRATE et al., 2010; ARAÚJO NETO et al., 2012).

No entanto, o cultivo da alface em regiões de alta luminosidade e temperatura, pode apresentar baixa produtividade e qualidade, devido a fotoinibição (FU; LI; WU, 2012), que é amenizado em cultivo protegido (SILVA et al., 2015). No estado do Acre, a precipitação pluviométrica também reduz a produtividade da cultura, exigindo cultivo protegido (LEDO et al., 2000). Esta produtividade é decorrente do menor tamanho de planta, 
portanto, influencia na formação do preço, exigindo estratégias tecnológicas tanto para aumentar a produtividade quanto para melhorar o rendimento econômico (ARAÚJO NETO et al., 2009; FERREIRA et al., 2009, 2014).

A cobertura do solo com plásticos proporciona maior controle de plantas espontâneas, menor evaporação da água do solo, economia de água de irrigação (FERREIRA et al., 2006, 2009; BRANCO et al., 2010) menor amplitude térmica do solo e maior rentabilidade econômica em comparação ao solo descoberto, tanto em cultivo protegido como a céu aberto (ARAÚJO NETO et al., 2009).

A aquisição e o manejo do plástico são fatores que aumentam o custo de produção (ARAÚJO NETO et al., 2009), sendo necessário explorar ao máximo o potencial produtivo desta tecnologia, alterando o número de plantas por cova. Que apesar de se observar redução da massa foliar de plantas de alface em até $22 \%$ quando se cultiva duas plantas por cova (MELO et al., 2010), pode haver ganho por área, como ocorre com a rúcula, em que o aumento da densidade de mudas por cova (de duas para quatro) proporciona maior rendimento em massa fresca por metro quadrado de canteiro (REGHIN; OTTO; VAN DER VINNE, 2004; REGHIN et al., 2005).

$\mathrm{O}$ aumento do número de plantas por cova no cultivo com cobertura plástica pode aumentar o número de unidades comerciais (maço), já que em condições de alta luminosidade e temperatura a planta de alface isolada apresenta baixo rendimento. O maço com mais de uma planta é a forma comercializada no Estado do Acre, com isso, o plantio de mais de uma planta por cova possibilita fracionar as covas para formar um maço, aumentando o rendimento econômico por área cultivada. Mas, o aumento do adensamento de plantio pode implicar em maior necessidade hídrica, maior fertilidade do solo e menor ciclo biológico causados principalmente pela intracompetição (OLIVEIRA et al., 2010; PÔRTO et al., 2012).

O objetivo deste trabalho foi avaliar a produtividade de alface do tipo crespa com diferentes números de plantas por cova em solo coberto com filme plástico.

\section{Material e Métodos}

O experimento foi conduzido no Sítio Ecológico Seridó, em Rio Branco, capital do Estado do Acre, situado na latitude de $9^{\circ} 53^{\prime} 16^{\prime}$ ' S e longitude de $67^{\circ} 49^{\prime} 11^{\prime}$ ' W, a uma altitude de $170 \mathrm{~m}$, em março de 2011 (ACRE, 2010). A área do experimento se encontrava há três anos em sistema orgânico de hortaliças.

O clima da região é quente e úmido, do tipo Am, segundo a classificação de Köppen, com temperaturas médias anuais variando em torno $24,5^{\circ} \mathrm{C}$, umidade relativa do ar de $84 \%$ e a precipitação anual varia de 1.700 a $2.400 \mathrm{~mm}$ (ACRE, 2010).

O solo da área experimental é classificado como ARGISSOLO AMARELO Plíntico. A análise química na camada de $0-20 \mathrm{~cm}$, apresentou $\mathrm{pH}=5,6$; M.O. $=51,3 \mathrm{~g} \mathrm{dm}^{-3} ; \mathrm{P}=256,5 \mathrm{mg} \mathrm{dm}^{-3}$; $\mathrm{K}=8,1 \mathrm{mmol}_{\mathrm{c}} \mathrm{dm}^{-3} ; \mathrm{Ca}=87,5 \mathrm{mmol}_{\mathrm{c}} \mathrm{dm}^{-3} ; \mathrm{Mg}=58 \mathrm{mmol}_{\mathrm{c}} \mathrm{dm}^{-3}$; $\mathrm{Al}=0,00 \mathrm{mmol}_{\mathrm{c}} \mathrm{dm}^{-3} ; \mathrm{H}+\mathrm{Al}=28,5 \mathrm{mmol}_{\mathrm{c}} \mathrm{dm}^{-3} ; \mathrm{SB}=153,6 \mathrm{mmol} \mathrm{dm}^{-3}$; $\mathrm{CTC}=182,1 \mathrm{mmol}_{c} \mathrm{dm}^{-3} ; \mathrm{V}=84,35 \% ; \mathrm{Ca} / \mathrm{Mg}=1,52 \mathrm{e} \mathrm{Mg} / \mathrm{K}=8,13$.

O preparo do solo constou de aração com arado de aiveca e gradagem com grade cultivadora de cinco facas e seis discos ambos puxados com cavalo. A adubação constou de $1,5 \mathrm{~kg} \mathrm{~m}^{-2}$ de composto orgânico (base seca) incorporado no momento de construção dos canteiros com enxada manual. Os canteiros foram irrigados por tubo gotejador mantendo lâmina diária de $6 \mathrm{~mm}$ e cobertos com plástico dupla face (branco/preto) perfurados no espaçamento de 0,30 x 0,30 m em triângulo.

A semeadura da cultivar Vera foi feita em bandejas de poliestireno expandido de 128 células, utilizando de 3 a 6 sementes por célula, que foi desbastado para 1, 2, 3 e 4 plântulas por células, e após 22 dias foi realizado o transplante e a colheita 32 dias após o transplantio. Utilizou-se substrato à base de terra, composto orgânico, esterco de curral e casca de arroz carbonizado em proporções iguais. Adicionou-se $10 \%$ de carvão vegetal triturado, $1,0 \mathrm{~kg}$ de calcário e $1,5 \mathrm{~kg}$ de termofosfato por $\mathrm{m}^{3}$ de substrato.

Utilizou-se casa de vegetação do tipo capela, de $30 \mathrm{~m}$ de comprimento e 4,60 m de largura, coberta com polietileno transparente de $100 \mu \mathrm{m}$ de espessura, com $1,80 \mathrm{~m}$ de pé direito e 3,5 m de altura central e laterais abertas.

O delineamento experimental foi em blocos ao acaso, com quatro tratamentos e seis repetições. Os tratamentos constituíram em 1, 2, 3 e 4 plantas por cova. A unidade experimental foi composta por parcelas medindo $1,8 \mathrm{~m}$ de comprimento por $1,2 \mathrm{~m}$ de largura no topo do canteiro espaçados por carreadores de $0,50 \mathrm{~m}$, com plantas dispostas em quatro fileiras, espaçadas de $0,30 \times 0,30 \mathrm{~m}$, totalizando 24 covas, que permitirão a densidade variando de 24 a 96 plantas por parcela. A área útil da parcela foi formada por 6 covas das duas linhas centrais do canteiro.

Os dados foram submetidos à análise de variância que ao se observar significância do teste $\mathrm{F}$ a $5 \%$ de probabilidade do erro, utilizou-se testes de regressão para determinar a função matemática que explique o fenômeno.

As variáveis analisadas foram: massa fresca comercial, medida após a colheita das plantas, efetuando-se a limpeza e remoção das folhas exteriores sujas e em processo de senescência, doentes e danificadas, pesadas em balança eletrônica e os resultados expressos em g.cova ${ }^{-1}$ e g.planta ${ }^{-1}$.

A Classe comercial foi determinada de acordo com as normas do programa brasileiro para padronização da horticultura (INSTITUTO..., 2007), baseado em limite inferior e superior de massa em gramas por planta (classes $5=<100 \mathrm{~g} ; 10=100$ a $<150$ g; $15=150$ a $<200$ g; $20=200$ a $<250$ g; $25=250$ a $<300 \mathrm{~g} ; 30=300 \mathrm{a}<350 \mathrm{~g} ; 35=350$ a $<400 \mathrm{~g} ; 40=400 \mathrm{a}<450 \mathrm{~g} ;$ $45=450 \mathrm{a}<500 \mathrm{~g}$; as classes seguem até $100=>1000 \mathrm{~g}$ ).

Para a produtividade comercial foi considerado o número de maço/ $\mathrm{m}^{2}$, considerou-se como maço: planta única, desde que pesando acima de $250 \mathrm{~g}$ (classe 25 ou superior) ou associação de duas ou mais plantas com massa fresca, que somasse pelo menos $250 \mathrm{~g}$. Assim, no tratamento com apenas uma planta por cova, foi considerado o número inteiro de 0,5 maço para parcelas que em média proporcionaram plantas $<250 \mathrm{~g}$; e 1,0 maço para parcelas que em média proporcionaram plantas com $\geq 250 \mathrm{~g}$. Mas para os tratamentos com 2, 3 e 4 plantas por cova, pela possibilidade de divisão do número de plantas por cova, foi considerado o número de maço médio da parcela dividindo-se o número total de plantas da parcela pela somatória de plantas que forma um maço com $\geq 250 \mathrm{~g}$. 


\section{Resultados e Discussão}

O número de plantas por cova afetou o desempenho da alface em relação às variáveis, massa fresca por planta e por cova, classe comercial e número de maço por $\mathrm{m}^{2}$. A massa fresca por planta apresentou redução linear da ordem de $61,2 \mathrm{~g} \mathrm{planta}^{-1}$ para cada planta associada, diminuindo de 239,59 g planta $^{-1}$ (1 planta cova ${ }^{-1}$ a 56,0 g planta ${ }^{-1}$ (4 plantas cova ${ }^{-1}$ ) (Figura 1).

Essa massa fresca por planta de 239,59 $\mathrm{g}$ é semelhante à massa fresca de alface observada em outros trabalhos desenvolvidos na região (CARVALHO et al., 2005; FERREIRA et al., 2009; LÊDO; SOUZA; SILVA, 2000), enquanto o cultivo em regiões de clima ameno, como em Seropédica-RJ (OLIVEIRA et al., 2006) e São Roque-SP (BRANCO et al., 2010), proporciona plantas com maior massa fresca, 348 g planta $^{-1}$ e 696,26 g planta $^{-1}$, respectivamente, que são comercializadas como unidade, não sendo preciso associar duas ou mais plantas para formar uma unidade comercial (maço).

Por depender da massa fresca da planta, a classe comercial de cada planta também reduziu linearmente 6,5 unidades para cada plantas associada na cova, reduzindo da classe 22,25 (1 planta cova $\left.{ }^{-1}\right)$ para 2,75 (4 plantas cova ${ }^{-1}$ ) (Figura 2).
Apesar da redução significativa da massa fresca da planta cultivada em associação de duas, três ou quatro plantas por cova, observou-se aumento linear de, 14,31 $\mathrm{g} \mathrm{cova}^{-1}$ para o aumento de cada unidade de planta por cova de cultivo (Figura 3) que consequentemente aumentou a produtividade comercial $\left(\right.$ maço $\left.\mathrm{m}^{-2}\right)$. O número de maço, aumentou linearmente de 11,2 maços $\mathrm{m}^{-2}$ (1 planta cova ${ }^{-1}$ ) para 14,06 maços $\mathrm{m}^{-2}$ (4 plantas cova ${ }^{-1}$ ), um aumento de 1,016 maço $\mathrm{m}^{-2}$ para cada planta associada (Figura 4). Apesar de o maior adensamento favorecer a produtividade, com o aumento da densidade, a massa fresca da planta individual diminui. $\mathrm{O}$ adensamento em hortaliças reduz em $25,2 \%$ a massa fresca e em $33 \%$ a produtividade (CECÍLIO-FILHO et al., 2011), reduz também, a área foliar, o número de folhas e a massa seca das folhas (SILVA et al., 2011). Em couve flor, reduz também o diâmetro do caule e a massa da inflorescência em couve-flor (PÔRTO et al., 2012).

Segundo Cecílio-Filho et al. (2011) esta redução na matéria fresca da parte aérea da planta é causado por ter seu crescimento limitado pela maior competição por $\mathrm{N}$ e outros fatores relacionados com o crescimento. E também em processo de competição intraespecífica, promovida pelo adensamento

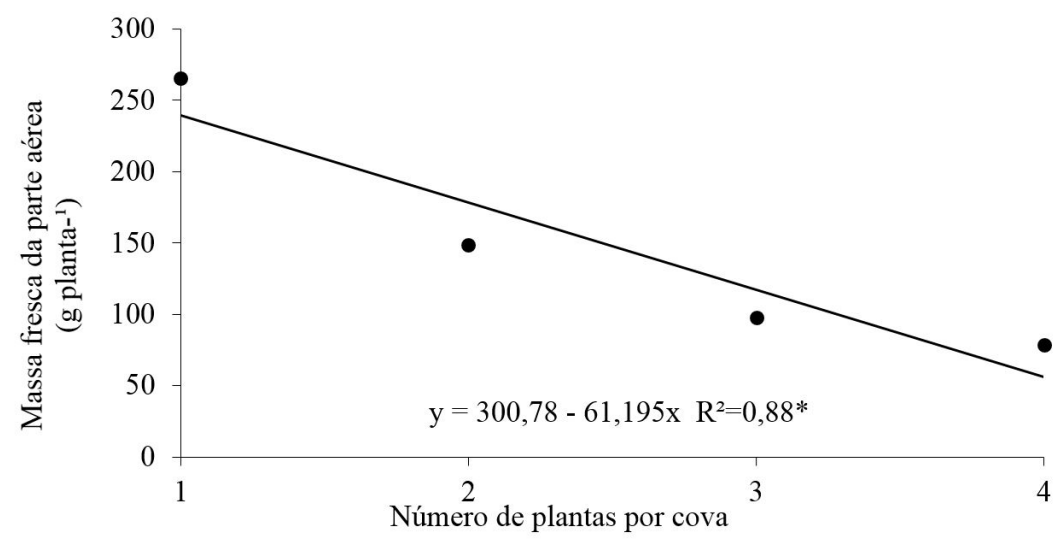

Figura 1. Massa fresca da parte aérea da alface cv. Vera em cultivo orgânico utilizando plástico dupla face como cobertura dos canteiros com diferentes números de plantas por cova. *Coeficiente de determinação. Fonte: Elaborado pelos autores.

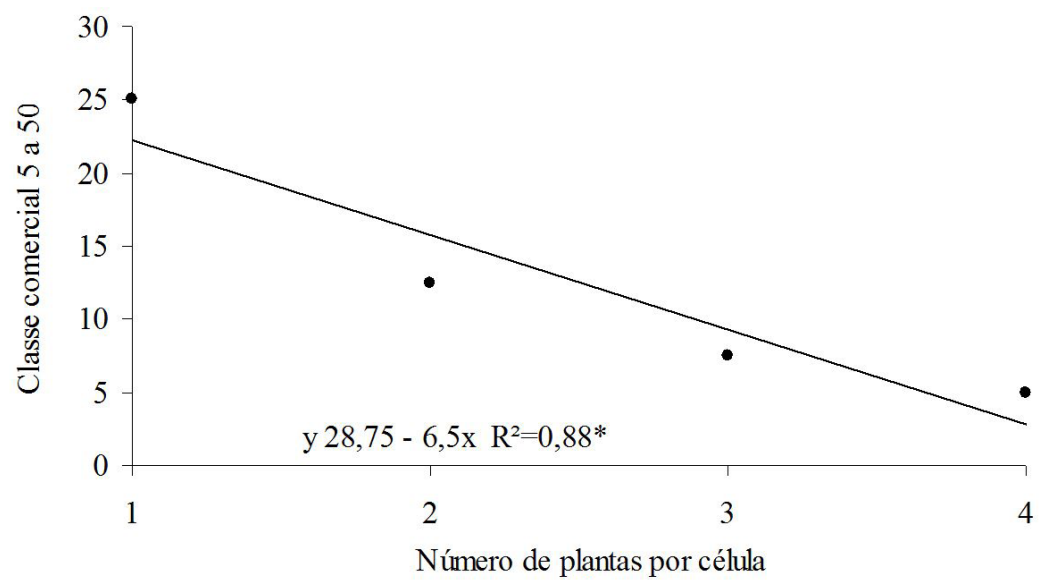

Figura 2. Classe comercial por planta de alface cv. Vera em cultivo orgânico utilizando plástico dupla face como cobertura dos canteiros com diferentes números de plantas por cova. *Coeficiente de determinação. Fonte: Elaborado pelos autores. 


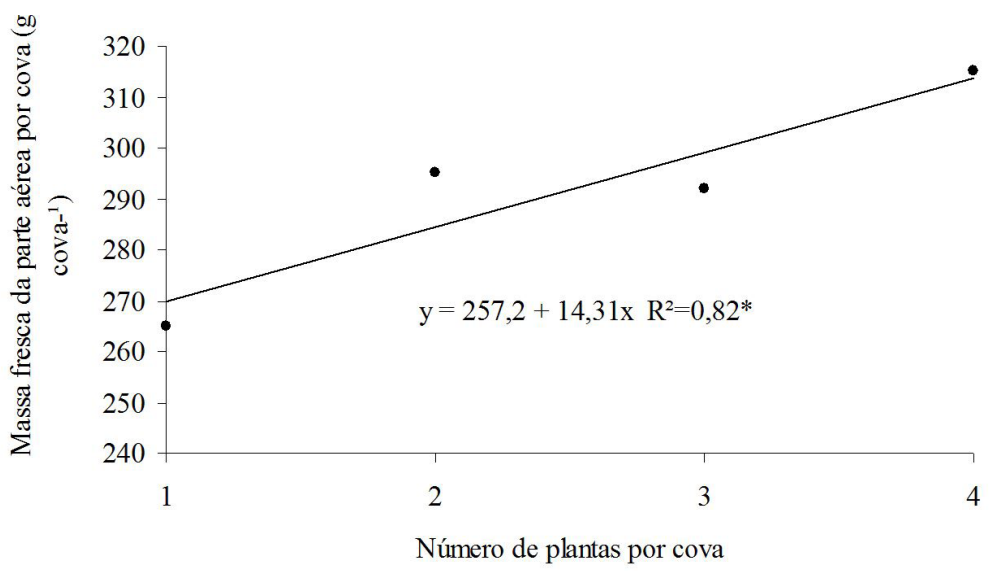

Figura 3. Massa fresca da parte aérea por cova $\left(\mathrm{g} \mathrm{cova}^{-1}\right)$ da alface cv. Vera em cultivo orgânico utilizando plástico dupla face como cobertura dos canteiros com diferentes números de plantas por cova. *Coeficiente de determinação. Fonte: Elaborado pelos autores.

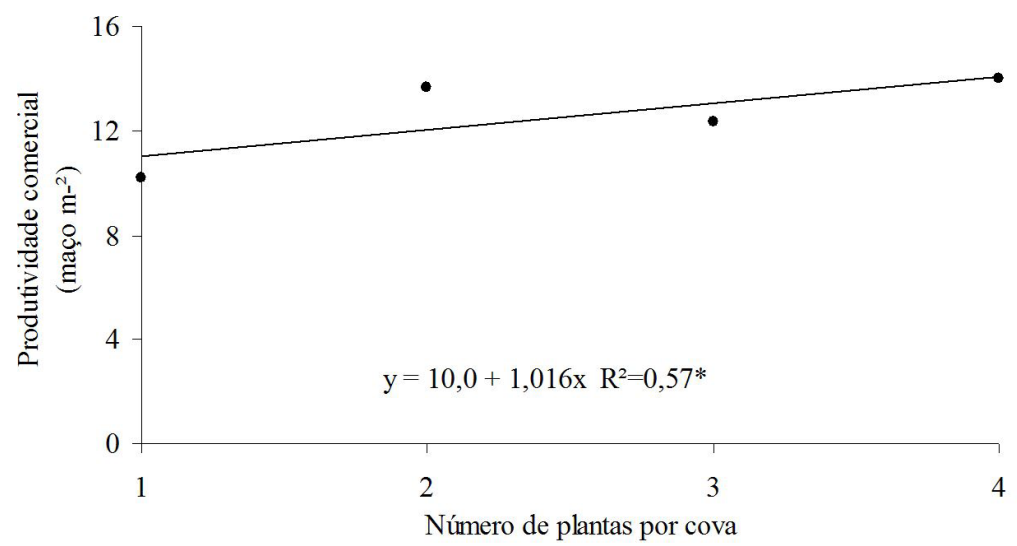

Figura 4. Produtividade comercial de alface cv. Vera em cultivo orgânico utilizando plástico dupla face como cobertura dos canteiros com diferentes números de plantas por cova. *Coeficiente de determinação. Fonte: Elaborado pelos autores.

populacional, mas não reduz a produtividade comercial de couve-flor (PÔRTO et al., 2012).

A diferença do número de maço $\mathrm{m}^{-2}$ entre o cultivo de quatro plantas e uma planta é de 2,86 maço $\mathrm{m}^{-2}$, extrapolando estes dados para uma estufa de cultivo que na região é comum medir 4,6 m x 50,0 m, com $180 \mathrm{~m}^{2}$ de área cultivada, esta diferença é de 514,8 maços, vendidos no valor local de $\mathrm{R} \$ 1,50$, proporciona uma renda adicional de $\mathrm{R} \$ 772,2$ por ciclo, valor significativo para os agricultores familiares que são os responsáveis pelo fornecimento de hortaliças no Estado do Acre. Araújo Neto et al. (2009), verificaram que o cultivo de alface sobre mulching com plástico dupla face (preto/branco) em ambiente protegido nas condições do Acre, proporciona rendimentos econômicos satisfatório, apesar de representar $6,12 \%$ do custo de produção e elevar o custo fixo, a produtividade de alface $30 \%$ maior que em solo descoberto, compensa o investimento e proporciona índice de retorno de 1,8 em ambiente protegido.

A redução da massa foliar de plantas de alface pode ocorrer com o aumento do número de plantas por cova. Essa redução é de $22 \%$, quando se cultiva duas plantas por cova ao invés de uma única planta (MELO et al., 2010). Cécílio-Filho et al. (2011) também observaram redução da massa fresca de plantas de repolho com o aumento da densidade e atribuíram este fenômeno à competição por espaço e demais fatores de produção.

Reghin, Otto e Van Der Vinne (2004) observaram resultados semelhantes para rúcula, outra hortaliça comercializada em maço e por isso, a densidade é o fator que contribui diretamente para o incremento do rendimento, aumentando o rendimento de $1,4 \mathrm{~kg} \mathrm{~m}^{-2}$ na densidade de uma muda por cova para $6,4 \mathrm{~kg}$ $\mathrm{m}^{-2}$ na densidade de quatro mudas.

\section{Conclusão}

O aumento da densidade de 1 a 4 plantas de alface por cova reduz linearmente a massa fresca da planta e a classe comercial, porém aumenta linearmente a massa fresca por cova e o número de unidades comerciais (maço) por unidade de área.

\section{Agradecimentos}

À Coordenação de Aperfeiçoamento de Pessoal de Nível Superior (CAPES) e ao Conselho Nacional de Desenvolvimento Científico e Tecnológico (CNPq) pela concessão de bolsa aos autores. 


\section{Referências}

ACRE. Governo do Estado. Secretaria de Estado de Planejamento e Desenvolvimento Econômico-Sustentável. Secretaria de Estado de Meio Ambiente e Recursos Naturais. Programa Estadual de Zoneamento Ecológico Econômico do Estado do Acre. Zoneamento ecológico-econômico do Acre Fase II: documento síntese Escala 1:250.000. 2. ed. Rio Branco: SEMA, 2010. 357 p.

ARAÚJO NETO, S. E. et al. Rentabilidade da produção orgânica de alface em função do ambiente, preparo do solo e época de plantio. Revista Ciência Agronômica, Fortaleza, v. 43, p. 783-791, 2012. http://dx.doi.org/10.1590/S1806-66902012000400021.

ARAÚJO NETO, S. E.; FERREIRA, R. L. F.; PONTES, F. S. T. Rentabilidade da produção orgânica de cultivares de alface com diferentes preparos do solo e ambiente de cultivo. Ciência Rural, Santa Maria, v. 39, n. 5, p. 1362-1368, 2009. http://dx.doi.org/10.1590/ S0103-84782009005000071.

BRANCO, R. B. F. et al. Cultivo orgânico sequencial de hortaliças com dois sistemas de irrigação e duas coberturas de solo. Horticultura Brasileira, Brasília, v. 28, p. 75-80, 2010. http://dx.doi.org/10.1590/ S0102-05362010000100014.

CARVALHO, J. E. et al. Cobertura morta do solo no cultivo de alface cv. Regina 2000, em Jiparaná/RO. Ciência e Agrotecnologia, Lavras, v. 29, n. 5, p. 935-939, 2005. http://dx.doi.org/10.1590/ S1413-70542005000500003.

CECÍLIO-FILHO, A. B. et al. Crecimiento y producción de repollo en función de la densidad de población y nitrógeno cabbage growth and production in relation to plant density and nitrogen. Agrociencia, México, v. 45, n. 5, p. 573-582, 2011.

FERREIRA, R. L. F. et al. Influência da cobertura de solo na produção do meloeiro. Revista de Ciências Agrárias, Belém, v. 46, p. 215-226, 2006.

FERREIRA, R. L. F. et al. Combinações entre cultivares, ambientes, preparo e cobertura do solo em características agronômicas de alface. Horticultura Brasileira, Brasília, v. 27, n. 3, p. 383-388, 2009. http://dx.doi.org/10.1590/S0102-05362009000300023.

FERREIRA, R. L. F. et al. Produção orgânica de alface em diferentes épocas de cultivo e sistemas de preparo e cobertura de solo. Bioscience Journal, Uberlândia, v. 30, p. 1017-1023, 2014.

FU, W.; LI, P.; WU, Y. Effects of different light intensities on chlorophyll fluorescence characteristics and yield in lettuce. Scientia Horticulturae, Amsterdam, v. 135, p. 45-51, 2012. http://dx.doi. org/10.1016/j.scienta.2011.12.004.

INSTITUTO BRASILEIRO DE QUALIDADE EM HORTICULTURA - HORTIBRASIL. Programa Brasileiro para a Modernização da Horticultura. Disponível em <http://www.hortibrasil.org.br/ classificacao/alface/alface.html>. Acesso em: 2 ago. 2007.
LÉDO, F. J. S.; SOUZA, J. A.; SILVA, M. R. Desempenho de cultivares de alface no estado do Acre. Horticultura Brasileira, Brasília, v. 18, p. 225-228, 2000. http://dx.doi.org/10.1590/ S0102-05362000000300017.

MEDEIROS, D. C. et al. Produção de mudas de alface com biofertilizantes e substratos. Horticultura Brasileira, Brasília, v. 25, n. 3, p. 433 436, 2007. http://dx.doi.org/10.1590/S0102-05362007000300021.

MELO, D. J. F. et al. Avaliação de cultivares de alface e número de plantas por célula, em cultivo hidropônico em ambiente tropical. Horticultura Brasileira, Brasília, v. 28, p. S297-S302, 2010.

OLIVEIRA, N. G. et al. Plantio direto de alface adubada com "cama" de aviário sobre coberturas vivas de grama e amendoim forrageiro. Horticultura Brasileira, Brasília, v. 24, p. 112-117, 2006. http:// dx.doi.org/10.1590/S0102-05362006000100023.

OLIVEIRA, R. P. et al. Influência do arranjo de plantas em dois híbridos de milho safrinha nas relações de interferência com a comunidade infestante. Revista Brasileira de Ciências Agrárias, Recife, v. 5, n. 4, p. 450-459, 2010. http://dx.doi.org/10.5039/agraria.v5i4a556.

PÔRTO, D. R. Q. et al. Densidade populacional e época de plantio no crescimento e produtividade da couve-flor cv. Verona 284. Revista Caatinga, Mossoró, v. 25, p. 92-98, 2012.

REGHIN, M. R. et al. Efeito do espaçamento e do número de mudas por cova na produção de rúcula nas estações de outono e inverno. Ciência e Agrotecnologia, Lavras, v. 29, n. 5, p. 953-959, 2005. http://dx.doi.org/10.1590/S1413-70542005000500006.

REGHIN, M. Y.; OTTO, R. F.; VAN DER VINNE, J. Efeito da densidade de mudas por célula e do volume da célula na produção de mudas e cultivo da rúcula. Ciência e Agrotecnologia, Lavras, v. 28, n. 2, p. 287-295, 2004. http://dx.doi.org/10.1590/S1413-70542004000200006.

SILVA, E. M. N. C. P. et al. Desempenho agronômico de alface orgânica influenciado pelo sombreamento, época de plantio e preparo do solo no Acre. Pesquisa agropecuária brasileira, Brasília, v. 50, n. 6, p. 468-474, 2015. http://dx.doi.org/10.1590/ S0100-204X2015000600005.

SILVA, G. S. et al. Espaçamentos entrelinhas e entre plantas no crescimento e na produção de repolho roxo. Bragantia, Campinas, v. 70, n. 3, p. 538-543, 2011.

SOUZA, S. R et al. Produção de mudas de alface em sistema floating sob tela de sombreamento e cobertura plástica. Revista Caatinga, Mossoró, v. 20, n. 3, p. 191-197, 2007.

ZÁRATE, N. A. H. et al. Produção agroeconômica de três variedades de alface: cultivo com e sem amontoa. Revista Ciência Agronômica, Fortaleza, v. 41, n. 4, p. 646-653, 2010. http://dx.doi.org/10.1590/ S1806-66902010000400019. 